\title{
Editorial: Brand research imperatives
}

The topic of branding and brand management has clearly become an important management priority in the past decade or so. Accordingly, academic research has covered a number of different issues that have collectively advanced our understanding of brands. Before considering imperatives in brand research, it is worthwhile to take some stock of the progress that has been made and the kinds of generalisation that have emerged from this academic research. The following comments are based on an in-depth review of academic research prepared as background for a chapter to appear in a handbook targeting graduate students in marketing. ${ }^{1}$

\section{SUMMARY OBSERVATIONS}

Prior academic research has convincingly demonstrated the power of brands. Branding effects are pervasive, and the impact of virtually any marketing activity seems to be conditioned or qualified by the nature of the brands involved. In particular, consumer response to a product and its prices, advertising, promotions and other aspects of the marketing programme have been shown to depend on the specific brands in question. In understanding how these effects are manifested, essentially all the theoretical approaches one way or another interpret these branding effects in terms of consumer knowledge about the brand and how that knowledge affects consumer behaviour. The particular dimensions or aspects of brand knowledge that drive these differences vary, however, by theoretical account and by the particular problem being investigated. Similarly, the exact mechanism involved also varies according to the brand setting under study.

Because of the primary explanatory role that brand knowledge plays as an antecedent, however, branding effects are highly dependent on the context involved. Highlighting brand-related information can activate certain brand associations and not others in a manner to produce different outcomes. This differential accessibility may be a result of the cues in the marketing environment from the marketing programme or through other means. Branding effects can thus be surprisingly complex. Moreover, there is inherent complexity with brands themselves as brand names, logos, symbols, slogans, etc all have multiple dimensions which each can produce differential effects on consumer behaviour.

As a result, brand management challenges can be especially thorny. There are a number of input variables that come into play and a number of outcome variables that may be of interest. Only by understanding the totality of the possible antecedents and consequences of brand marketing activity and the possible mechanisms involved can proper analysis be conducted and decisions executed. 


\section{BRAND RESEARCH IMPERATIVES}

Although much progress has been made in branding research, especially in the last decade or so, a number of important research priorities exist which suggest that branding will be a fertile area for research for years to come. Five general areas worthy of some research emphasis can be highlighted.

- Develop richer, more comprehensive and actionable models of brand equity. There is still a need to develop more fully articulated models of brand equity that provide greater expository detail and which are useful in aiding managers across a broad range of decision settings. At the same time, there also needs to be more parsimonious representations of these models to facilitate their applicability and use. Because of their central role, models that provide a more complete articulation of brand knowledge are especially needed. Along those lines, more work needs to be done to better conceptualise 'brand intangibles' in terms of structure and processes.

- Design better 'brand metrics' and more insightful measures of brand equity. As in virtually any area of marketing, there is a need to develop more insightful, diagnostic measures of branding phenomena. As is often the case, this will clearly involve multiple methods and measures. As suggested above, different decision makers have different interests and will therefore require different types of information. To practising managers, it is especially important to develop better measures that are able to directly relate marketing activity to actual brand performance. To senior management, it is especially important to develop highly reliable brand valuation techniques and means of assessing returns on brand investments. Of critical importance in that regard is achieving a better understanding of the value and contribution of brands in various joint branding contexts and arrangements - be it with another brand, a person, an event, or whatever.

- Obtain a greater understanding of how meaning 'transfers' to and from brands. As brands are often linked with other entities - people, places, companies, brands, events, etc - it is important to understand how the knowledge about these other entities impacts brand knowledge. In what ways do the images of country of origin or country of brand, celebrity spokespeople, retail store, etc change or supplement the image of a brand? At the same time, it is important to understand how the meaning of a brand transfers to other brands, products, etc.

- Consider organisational 'internal' branding issues. A relatively neglected area of branding is prescriptive analysis of how different types of firms should best be organised for brand management. Additionally, there needs to be more insight into how to align brand management within the organisation, and those efforts directed to existing or prospective customers outside the organisation.

- Develop more refined models for specific application areas of branding. Finally, greater attention must be applied to understanding similarity and differences in branding for different 
types of application areas. Obviously, one priority area of study is 'virtual' branding and how brands should be built on the Internet. In a general sense, how broadly applicable are the guidelines that emerge from academic research? Which principles are valid and which ones need to be modified or supplemented in some way?

The challenge in pursuing research in these various areas will be to achieve the necessary rigour to satisfy the highest academic standards while also achieving the necessary relevance to satisfy the most demanding industry practitioners.

\section{Kevin Lane Keller Editorial Board}

\section{References}

(1) Keller, K. L. (2001) 'Branding and brand equity', in Weitz, B. and Wensley, R. (Eds) 'Handbook of Marketing', forthcoming. 